\title{
Implementation of an Educational Intervention to Optimize Self- Management and Transition Readiness in Young Adults with Sickle Cell Disease
}

\author{
Cecelia L. Calhoun ${ }^{1,3}$, Regina A. Abel ${ }^{2}$, Hai Ahn Pham ${ }^{4}$, Shomari Thompson ${ }^{5}$, and Allison \\ A. King ${ }^{1,2,3}$ \\ ${ }^{1}$ Department of Pediatrics, Division of Hematology Oncology, Washington University School of \\ Medicine, \\ 2Department of Pediatrics, Division of Hematology Oncology, Program in Occupational Therapy \\ ${ }^{3}$ Department of Pediatrics, Division of Hematology OncologySiteman Cancer Center, \\ ${ }^{4}$ Department of Pediatrics, Division of Hematology Oncology, Brown University \\ ${ }^{5}$ Department of Pediatrics, Division of Hematology Oncology, Meharry Medical College School of \\ Medicine
}

\section{Abstract}

Background-The transition from the pediatric setting to adult care is a well-described period of morbidity and mortality for persons with sickle cell disease (SCD). We sought to measure the feasibility and effectiveness of providing skill-based educational handouts on improving selfmanagement and transition readiness in adolescents with SCD.

Methods-This was a single center study in which participants completed a self-assessment, the Adolescent Autonomy Checklist (AAC), to assess transition readiness and self-management skills at baseline. After results were reviewed by the study coordinator, participants were provided with skill-based handouts on noted areas of deficit. The AAC was subsequently completed at a followup visit. All data were stored electronically and transferred into SAS for statistical analyses.

Results-Sixty-one patients completed the AAC at baseline and post-intervention. At baseline, patients reported needing the most help with skills in money management, living arrangements, vocational skills, and emergency and healthcare skills. Post-intervention, statistically significant improvements ( $\mathrm{p}<0.05$ ) occurred in skills related to laundry, housekeeping, healthcare, and sexual development. A regression model exploring the time to follow-up showed that most improvements could not be attributed to maturation alone.

Conclusion-This study showed that educational handouts are a readily implementable and well-accepted intervention among adolescents with SCD who identify challenges with skills necessary to successfully transition to adult care. Distinguishing which transition needs are best

Corresponding Author: Cecelia L. Calhoun, Washington University School of Medicine, Department of Pediatrics, 660 S. Euclid, Campus Box 8116, St. Louis, MO 63110, Phone: 314-454-6018, Fax: 314-454-2780, calhounc@wustl.edu.

Conflict of Interest Statement

The authors have no conflicts of interest to declare. 
improved with this type of intervention will help to strengthen the multidisciplinary approach necessary to support adolescents and young adults with SCD as they matriculate to adult care.

\section{Keywords}

sickle cell disease; transition; young adult; education

\section{Introduction}

Sickle cell disease (SCD) is an autosomal recessive condition affecting over 100,000 people in the United States, with approximately 1,000 new births each year. ${ }^{1}$ It is the most common genetic disorder in the United States, affecting approximately 1 in 350 African American births. ${ }^{2}$ Clinically, SCD manifests in a variety of ways including significant end organ damage, debilitating pain, severe pulmonary compromise, and cerebrovascular injury. In addition, SCD accounts for approximately $\$ 488$ million in annual healthcare costs. ${ }^{3}$ The implementation of prophylactic penicillin and the use of disease-modifying medications, namely Hydroxyurea, have resulted in improved health outcomes for patients with SCD. ${ }^{4}$ However, the rates of mortality in adolescents and young adults with SCD (AYA-SCD) have remained relatively unchanged. ${ }^{1}$ These patients are at greatest risk for mortality during the transition from pediatric to adult healthcare. ${ }^{5}$ Similar to other chronic childhood conditions, the transition period in the AYA-SCD population represents a vulnerable window, as it is the intersection between normal adolescent development, progression of disease complications, and change in environmental resources. The need for structured, multidisciplinary interventions to improve transition outcomes in the AYA-SCD population is well established. ${ }^{6}$ Developing strategies that are readily implementable is the next step in optimizing outcomes in this population.

Current literature has demonstrated the utility and effectiveness of educational interventions in improving transition outcomes in chronic pediatric conditions such a congenital heart disease and diabetes. ${ }^{7-11}$ Using an educational approach may be ideal in the SCD population, as cerebrovascular injury and cognitive impairment are hallmarks of the disease. 12 Prior to Transcranial Doppler screening and transfusion therapy, patients with the most severe genotypes (SS and $\mathrm{S} \beta^{\text {thal0 }}$ ), have an absolute risk of overt stroke of $11 \%$ by 20 years of age, with a cumulative stroke risk of $12.8 \%$ by age $20 .{ }^{13}$ In addition, the risk of a silent cerebral infarction is $40 \%$ by age $18^{14}$ and $50 \%$ by age 30 for those with severe genotypes. ${ }^{15}$ Furthermore, deficits in full scale IQ and executive functioning have been reported even in the absence of an acute cerebrovascular accident. ${ }^{16}$ The successful use of educational interventions has been described in the pediatric SCD population, but there is a paucity of literature that specifically focuses on the transition period. ${ }^{17,18}$ This study sought to explore the feasibility and effectiveness of educational interventions on this high-risk subpopulation.

Our prior work demonstrated that adolescents with SCD self-identify challenges with transition to adult care. Previously, we used the Adolescent Autonomy Checklist (AAC) modified to include SCD-specific tasks (AAC-SCD) that patients with SCD need to practice in order to successfully transition to adult healthcare and independent living. ${ }^{19}$ This single center study used the AAC-SCD to measure the effectiveness of skill-based educational 
handouts on improving self-management and transition readiness in adolescents with SCD. We hypothesized that a streamlined educational intervention was a feasible and readily implementable method to improve transition skills in this high-risk population.

\section{Methods}

IRB approval was obtained from the Washington University Institutional Review Board for this single center, retrospective cohort study. Patients were recruited from the pediatric hematology clinic at St. Louis Children's Hospital. Patients 13-21 years of age with SCD of any genotype were invited to participate. An additional inclusion criterion included the successful completion of the AAC-SCD both before and after the educational intervention. Patients who did not speak English were excluded from participation.

\section{Instrumentation and Procedures}

The AAC is a 100-item measure developed by the Youth in Transition Project at the University of Washington Division of Adolescent Medicine. ${ }^{19,20}$ It assesses the skill level of adolescents in completing activities necessary for self-care and independent living. In the clinical setting, the AAC does not have a scoring rubric, but rather helps providers identify where to target education. The AAC assesses 100 skills across 12 domains. The AAC-SCD is a 100-item tool that incorporates skills specifically associated with management of SCD. 19 The AAC-SCD assesses 100 skills over 12 domains and has been amended to better address the needs of patients with SCD by increasing the number of health-related skills assessed and including additional domains which are relevant to the young adult SCD population such as money management and sexual development (Supplemental Material S1). AAC-SCD domains include kitchen, nutrition, laundry, housekeeping, emergency management, personal skills, healthcare skills, money management, sexual development, leisure skills, vocational skills, and living arrangements. Respondents were asked to mark "can do already," "needs practice," "plan to start," or "accomplished" for each item to indicate their perceived ability to complete each skill.

One-page educational fact sheets were developed by the study team that correspond with each item on the AAC-SCD. These handouts were thoughtfully created by our research team which included pediatric hematologists, occupational therapists and clinic educators. Once created, the handouts were again reviewed for accuracy and clarity. These tools were designed to provide patients with a brief introduction to each topic, with content varying from broad educational information to specific step-by-step directions and illustrations. Literacy levels and age were considered when developing the educational tools (Supplemental Material 2).

As a standard of care, participants completed the AAC-SCD at baseline, which took patients an average of 10-15 minutes. After the baseline assessment was reviewed by the study coordinator, participants randomly received up to five educational handouts based on the items they marked "needs practice." Patients reviewed these educational tools without supervision from the study team. Participants repeated the AAC-SCD at a subsequent clinic visit. In addition to baseline and follow-up AAC-SCD data, medical, educational and demographic data were collected via chart abstraction. Academic support was defined as the 
presence or absence of formal academic accommodations such as an Individualized Education Program (IEP) or 504 Plan. Any history of cerebrovascular insult was noted as well as whether the participant was on hydroxyurea at the time of survey administration. All data was entered into a REDCap Database by a research assistant for analysis.

\section{Statistical Analysis}

The primary outcome of this study was the feasibility of this intervention as measured by the number of subjects approached who enrolled in the study. Our secondary outcome was the improvement in transition skills as measured by the increase in items marked "Can Do". Data were examined for missing values to determine the number of participants who completed both baseline and follow-up evaluations. Key demographics were examined for those who completed the survey at both time points versus those who did not. Two group $t$ tests were used to assess the baseline and follow-up skill level reported as "can do" by participants. To explore the possibility of maturation as an explanation for improvement in skills, we included time to follow-up as a proxy for maturation in regression models. The longer the gap between baseline and follow-up, the more time the participant had to mature and develop these skills. We controlled for time to follow-up and its relationship to followup need by entering time to follow-up into the model before baseline need. Therefore, after accounting for the variance explained by maturation, the unique contribution of baseline need could be determined. All data were analyzed in SAS ${ }^{\circledR}$ statistical software (SAS Institute, Inc., Cary, NC). The General Linear Model procedure was used to look at Type III sums of squares for the unique contribution of each independent variable in the models.

\section{Results}

All 122 approached patients agreed to complete the baseline AAC-SCD and received educational handouts. All patients within the targeted age range were approached as staff were available and patients presented for well visits. During the study period, approximately half of the original participants had to transition their clinical care to another local healthcare system due to changes in Medicaid contracting. Of the remaining group, 61 patients returned to clinic and completed the follow-up AAC-SCD. Demographics of the study population are reported in Table 1. After analyzing for key demographic differences in those who completed the assessment at both time points versus those who did not, we found no difference based upon gender, insurance type, history of stroke, or presence of formal educational support. However, patients with HbSC were more likely to complete the followup measure as compared to patients with $\mathrm{HbSS}, \mathrm{HbS} \beta^{+}$, or $\mathrm{HbS}^{0}(\mathrm{p}=0.025)$. Also, those who completed the follow-up measure were younger on average by 1.4 years $(\mathrm{p}<0.0015)$.

At baseline, patients reported needing the most help with skills in money management, living arrangements, vocational skills, emergency management, and healthcare skills. Postintervention, statistically significant changes ( $\mathrm{p}$ 0.05) occurred in skills related to laundry, housekeeping, healthcare, and sexual development (Table 2). At both baseline and followup, patients were noted to skip questions; thus, the sample size for difference scores is lower than 61 for all 12 competency areas. 
Mean follow-up time was 333.8 days $(\mathrm{SD}=143.3)$, with a range of 161-882 days.

Regression modeling showed that time to follow-up was not a significant factor in predicting need in the domains of kitchen, nutrition, laundry, emergency management, personal skills, healthcare skills, money management, leisure time, or vocational skills (Table 3). However, time to follow-up did play a significant role in predicting need at follow-up in the areas of sexual development and living arrangements. In all models, baseline need was a significant predictor of post need, providing evidence that the starting point is important and that the changes in reported skill performance were not explained by maturation alone.

\section{Discussion}

Our results suggest that a clinic-based educational intervention is an easily implementable tool to improve transition skills in adolescents and young adults with SCD. This low-cost intervention was readily accepted by the study population and was easily integrated into the clinical setting with minimal burden. This type of educational intervention is optimal for young adults, as it is an on-site, visual tool that can support verbal education provided by the clinician.

Younger patients were more likely to complete the follow-up assessments, suggesting that providing skill-based education at an early age will provide more opportunities for prospective data collection and reinforcement of gained knowledge. Additionally, the intervention resulted in improved skills in tasks needed to transition to adult care, most notably those related to healthcare skills. Our regression model demonstrated that improvement in this area was not likely due to maturation alone. For patients transitioning from the pediatric to adult healthcare models, results indicate that educational interventions are not only acceptable, but also positively affect patients' ability to independently manage their care and daily function.

The lack of transition readiness amongst adolescents is well described. The goal of this study was to explore the role of an educational intervention and an avenue to mitigate these gaps in knowledge. This study is a promising starting point for the design and implementation of simple, knowledge-based clinic interventions and demonstrates the feasibility of this approach. Further investigation with a randomized controlled trial is warranted to address several limitations of this study. First, the AAC-SCD is a self-report measure that relies on the subjective perception of participants in addressing their own knowledge gaps. This measure was chosen as it was readily implemented in our clinic setting and previously used by our group. However, there is no scoring rubric from which to derive a normative range. Additionally, the measure has not yet been validated in the SCD population. Future studies will employ a validated transition readiness assessment, as well as validated measures of health literacy, to understand the baseline knowledge level of participants. This study employed a low-touch intervention with modest results and highlights skill areas that are most amenable to intervention. Future intervention design may incorporate more elaborate educational methods to address a broad range of reported deficits. Additionally, specifically targeting the reported deficit rather than administering a broad intervention may have a greater impact on skill improvement. Also, we will strive to have more a more defined approach to education and follow up to facilitate multilevel 
analyses of contributing factors. Fidelity to the intervention needs to be assessed as a potential moderator of final impact. Post-intervention analysis at more frequent and regular intervals may also elucidate the optimal time for follow-up testing. Lastly, a significant portion of the study population was diverted to an alternative healthcare system due to insurance limitations. This was an unfortunate consequence of the tenuous health care challenges faced by this population.

Overall, this study provides favorable evidence that skill-based knowledge among young adult patients with SCD can be readily improved by educational interventions. Strengthening health knowledge and self-management is crucial to improving patient outcomes during the high-risk period of transition to adult care. Decreasing morbidity and mortality in the AYASCD population will require structured and thoughtful collaboration among patients, caregivers, and providers. This study provides insight into methods that are feasible, acceptable, and effective.

\section{Supplementary Material}

Refer to Web version on PubMed Central for supplementary material.

\section{Acknowledgements}

Research reported in this publication was supported by the Eunice Kennedy Shriver National Institute of Child Health \& Human Development (NICHD)

Training Program in Developmental Hematology of the National Institutes of Health under award number 5T32HD007499 and the Health Resources and Services Administration under award number U1EMC27865.

The data that support the findings of this study are available from the corresponding author upon reasonable request.

\section{Abbreviations:}

$\begin{array}{ll}\text { AAC } & \text { Adolescent Autonomy Checklist } \\ \text { AAC-SCD } & \text { Sickle Cell-Specific Adolescent Autonomy Checklist } \\ \text { AYA-SCD } & \text { Adolescents and young adults with sickle cell disease } \\ \text { HbS }^{\mathbf{0}} & \text { Hemoglobin S beta thalassemia null } \\ \text { HbS }^{+} & \text {Hemoglobin S beta thalassemia plus } \\ \text { HbSC } & \text { Hemoglobin SC } \\ \text { HbSS } & \text { Hemoglobin SS } \\ \text { SCD } & \text { Sickle cell disease }\end{array}$

\section{References}

1. Hassell KL. Population estimates of sickle cell disease in the U.S. American journal of preventive medicine. 2010;38(4 Suppl):S512-521. [PubMed: 20331952] 
2. Brousseau DC, Owens PL, Mosso AL, Panepinto JA, Steiner CA. Acute care utilization and rehospitalizations for sickle cell disease. Jama. 2010;303(13):1288-1294. [PubMed: 20371788]

3. Steiner CA, Miller JL. Sickle Cell Disease Patients in U.S. Hospitals, 2004: Statistical Brief \#21 In: Healthcare Cost and Utilization Project (HCUP) Statistical Briefs. Rockville (MD): Agency for Healthcare Research and Quality (US); 2006.

4. Quinn CT, Rogers ZR, McCavit TL, Buchanan GR. Improved survival of children and adolescents with sickle cell disease. Blood. 2010;115(17):3447-3452. [PubMed: 20194891]

5. Hamideh D, Alvarez O. Sickle cell disease related mortality in the United States (1999-2009). Pediatric blood \& cancer. 2013;60(9):1482-1486. [PubMed: 23637037]

6. DeBaun MR, Telfair J. Transition and sickle cell disease. Pediatrics. 2012;130(5):926-935. [PubMed: 23027174]

7. Ladouceur M, Calderon J, Traore M, et al. Educational needs of adolescents with congenital heart disease: Impact of a transition intervention programme. Archives of cardiovascular diseases. 2017;110(5):317-324. [PubMed: 28342658]

8. Peters A, Laffel L. Diabetes care for emerging adults: recommendations for transition from pediatric to adult diabetes care systems: a position statement of the American Diabetes Association, with representation by the American College of Osteopathic Family Physicians, the American Academy of Pediatrics, the American Association of Clinical Endocrinologists, the American Osteopathic Association, the Centers for Disease Control and Prevention, Children with Diabetes, The Endocrine Society, the International Society for Pediatric and Adolescent Diabetes, Juvenile Diabetes Research Foundation International, the National Diabetes Education Program, and the Pediatric Endocrine Society (formerly Lawson Wilkins Pediatric Endocrine Society). Diabetes care. 2011;34(11):2477-2485. [PubMed: 22025785]

9. Goossens E, Van Deyk K, Zupancic N, Budts W, Moons P. Effectiveness of structured patient education on the knowledge level of adolescents and adults with congenital heart disease. Eur J Cardiovasc Nurs. 2014;13(1):63-70. [PubMed: 23420323]

10. Pyatak EA, Carandang K, Vigen CLP, et al. Occupational Therapy Intervention Improves Glycemic Control and Quality of Life Among Young Adults With Diabetes: the Resilient, Empowered, Active Living with Diabetes (REAL Diabetes) Randomized Controlled Trial. Diabetes care. 2018;41(4):696-704. [PubMed: 29351961]

11. Abualula NA, Jacobsen KH, Milligan RA, Rodan MF, Conn VS. Evaluating Diabetes Educational Interventions With a Skill Development Component in Adolescents With Type 1 Diabetes: A Systematic Review Focusing on Quality of Life. Diabetes Educ. 2016;42(5):515-528. [PubMed: 27402637]

12. King AA, DeBaun MR, White DA. Need for cognitive rehabilitation for children with sickle cell disease and strokes. Expert review of neurotherapeutics. 2008;8(2):291-296. [PubMed: 18271713]

13. Bernaudin F, Verlhac S, Arnaud C, et al. Impact of early transcranial Doppler screening and intensive therapy on cerebral vasculopathy outcome in a newborn sickle cell anemia cohort. Blood. 2011;117(4):1130-1140; quiz 1436. [PubMed: 21068435]

14. DeBaun MR, Kirkham FJ. Central nervous system complications and management in sickle cell disease. Blood. 2016;127(7):829-838. [PubMed: 26758917]

15. Kassim AA, Pruthi S, Day M, et al. Silent cerebral infarcts and cerebral aneurysms are prevalent in adults with sickle cell anemia. Blood. 2016;127(16):2038-2040. [PubMed: 26941400]

16. King AA, Rodeghier MJ, Panepinto JA, et al. Silent cerebral infarction, income, and grade retention among students with sickle cell anemia. American journal of hematology. 2014;89(10):E188-192. [PubMed: 25042018]

17. Porter JB, Evangeli M, El-Beshlawy A. Challenges of adherence and persistence with iron chelation therapy. International journal of hematology. 2011;94(5):453-460. [PubMed: 21993873]

18. Morrison-Levy N, Knight-Madden J, Royal-Thomas T, King L, Asnani M. Improving disease knowledge in 6- to 10-year-olds with sickle cell disease: A quasi-experimental study. Child: care, health and development. 2018;44(3):501-506.

19. Abel RA, Cho E, Chadwick-Mansker KR, D’Souza N, Housten AJ, King AA. Transition Needs of Adolescents With Sickle Cell Disease. The American journal of occupational therapy : official 
publication of the American Occupational Therapy Association. 2015;69(2): 6902350030p6902350031-6902350035.

20. A MAG study of the biomedical and psychosocial factors that predict independence in activities of daily living, academic success, and self-perceptions of children with myelomeningocele In.

(Unpublished doctoral dissertation). University of Washington, Seattle1990. 


\section{TABLE 1}

Demographics of Study Population

\begin{tabular}{|c|c|c|}
\hline Variable & Mean (Range) & $\begin{array}{l}\text { Standard } \\
\text { Deviation }\end{array}$ \\
\hline Age (years) & $\begin{array}{l}16.1(12.0-21.0) \\
\text { Frequency }\end{array}$ & $\begin{array}{l}2.6 \\
\text { Percent }\end{array}$ \\
\hline \multicolumn{3}{|l|}{ Sex } \\
\hline Male & 61 & 50 \\
\hline Female & 61 & 50 \\
\hline \multicolumn{3}{|l|}{ Phenotype } \\
\hline $\mathrm{HbSS}$ & 71 & 58.2 \\
\hline $\mathrm{HbSC}$ & 32 & 26.2 \\
\hline $\mathrm{HbS}^{+}$ & 10 & 8.2 \\
\hline $\mathrm{HbS} \beta^{0}$ & 8 & 6.6 \\
\hline \multicolumn{3}{|c|}{ Academic Support } \\
\hline Yes & 33 & 27.0 \\
\hline No & 89 & 73.0 \\
\hline \multicolumn{3}{|c|}{ Insurance Type } \\
\hline Private & 54 & 44.3 \\
\hline Medicaid & 63 & 51.6 \\
\hline None & 4 & 3.3 \\
\hline \multicolumn{3}{|c|}{ History of Cerebrovascular Accident } \\
\hline Yes & 41 & 33.6 \\
\hline No & 78 & 63.9 \\
\hline \multicolumn{3}{|c|}{ Hydroxyurea Therapy } \\
\hline Yes & 50 & 41.0 \\
\hline No & 71 & 58.2 \\
\hline
\end{tabular}

Pediatr Blood Cancer. Author manuscript; available in PMC 2020 July 01. 


\section{TABLE 2}

Mean Number of Skill Categories per Domain Marked "Can Do” among Adolescents with Sickle Cell Disease

\begin{tabular}{|c|c|c|c|}
\hline $\begin{array}{l}\text { AAC-SCD Categories (No. } \\
\text { of Items) }\end{array}$ & $\begin{array}{l}\text { Baseline } \\
\text { (SD) }\end{array}$ & $\begin{array}{l}\text { Follow-Up } \\
\quad \text { (SD) }\end{array}$ & $\begin{array}{c}\text { Mean } \\
\text { Difference (SD) }\end{array}$ \\
\hline Kitchen (4) & $3.95(0.22)$ & $3.84(0.55)$ & $-0.10(0.48)$ \\
\hline Nutrition (6) & $5.12(1.30)$ & $5.26(1.16)$ & $0.29(1.23)$ \\
\hline Laundry (6) ${ }^{*}$ & $5.32(1.20)$ & $5.56(0.90)$ & $0.25(0.94)$ \\
\hline Housekeeping (6) ${ }^{*}$ & $5.51(1.09)$ & $5.74(0.65)$ & $0.26(0.95)$ \\
\hline Emergency (4) & $3.00(1.14)$ & $3.19(1.12)$ & $0.21(1.07)$ \\
\hline Personal Skills (6) & $5.34(0.86)$ & $5.51(0.70)$ & $0.11(0.87)$ \\
\hline Healthcare Skills (32) ${ }^{*}$ & $24.51(7.84)$ & $26.18(6.44)$ & $1.59(5.01)$ \\
\hline Sexual Development (6) ${ }^{*}$ & $5.00(1.79)$ & $5.49(1.22)$ & $0.5(1.66)$ \\
\hline Money Management (6) & $4.19(2.22)$ & $4.34(2.11)$ & $0.14(2.22)$ \\
\hline Leisure Skills (13) & $11.84(1.78)$ & $12.20(1.41)$ & $0.44(1.83)$ \\
\hline Vocational Skills (6) & $4.48(1.97)$ & $4.90(1.88)$ & $0.51(2.08)$ \\
\hline Living arrangements (5) & $3.50(1.92)$ & $3.76(1.67)$ & $0.46(1.64)$ \\
\hline \multicolumn{4}{|l|}{ Indicates $\mathrm{p}<0.05$ (bolded) } \\
\hline aries from $55-61$ for each & gory. & & \\
\hline
\end{tabular}

Pediatr Blood Cancer. Author manuscript; available in PMC 2020 July 01. 
TABLE 3

Regression Model for Maturation

\begin{tabular}{|c|c|c|}
\hline Post Test Ability Domain & $\begin{array}{c}\text { Baseline Parameter } \\
\text { Estimate }\end{array}$ & $\begin{array}{c}\text { Maturation Parameter } \\
\text { Estimate }\end{array}$ \\
\hline Kitchen & 0.83 & 0.0006 \\
\hline Nutrition & $0.58^{* * * *}$ & -0.0006 \\
\hline Laundry & $0.65^{* * * *}$ & 0.0007 \\
\hline Housekeeping & 0.0000 & 0.0000 \\
\hline Emergency & $0.82^{* * * * *}$ & 0.0001 \\
\hline Personal Skills & $0.40^{* *}$ & -0.0007 \\
\hline Healthcare Skills & $0.58^{* * * *}$ & 0.004 \\
\hline Sexual Development & $0.63^{* * * *}$ & $0.002^{* *}$ \\
\hline Money Management & $0.37^{*}$ & -0.002 \\
\hline Leisure Skills & $0.40^{*}$ & 0.002 \\
\hline Vocational Skills & $0.38^{* *}$ & 0.0017 \\
\hline Living Arrangements & $0.66^{* * * * *}$ & $0.0026^{*}$ \\
\hline \multicolumn{3}{|l|}{ * 0.05} \\
\hline \multicolumn{3}{|l|}{$* *<0.01$} \\
\hline \multicolumn{3}{|l|}{$* * * * 0.001$} \\
\hline$\stackrel{* * * * *}{<}<0.0001$ & & \\
\hline
\end{tabular}

